\title{
Endectocides as a complementary intervention in the malaria control program: a systematic review
}

Fereshteh Ghahvechi Khaligh ${ }^{1,2}$, Abbas Jafari ${ }^{3,4}$, Elena Silivanova ${ }^{5}$, Mikhail Levchenko ${ }^{5}$, Bahlol Rahimi ${ }^{6}$ and Saber Gholizadeh ${ }^{1,2^{*}}$ (D)

\begin{abstract}
Background: Malaria is the most common vector-borne disease transmitted to humans by Anopheles mosquitoes. Endectocides and especially ivermectin will be available as a vector control tool soon. The current review could be valuable for trial design and clinical studies to control malaria transmission.

Methods: PubMed/MEDLINE, Scopus, Web of Science, and Science Direct were searched for original English published papers on ("Malaria chemical control" OR "Malaria elimination" OR "Anopheles vector control" OR "Malaria zooprophylaxis") AND ("Systemic insecticides" OR "Endectocides" OR "Ivermectin"). The last search was from 19 June 2019 to 31 December 2019. It was updated on 17 November 2020. Two reviewers (SG and FGK) independently reviewed abstracts and full-text articles. Data were extracted by one person and checked by another. As metaanalyses were not possible, a qualitative summary of results was performed.

Results: Thirty-six published papers have used systemic insecticides/endectocides for mosquito control. Most of the studies (56.75\%) were done on Anopheles gambiae complex species on doses from $150 \mu \mathrm{g} / \mathrm{kg}$ to $400 \mu \mathrm{gg} / \mathrm{kg}$ in several studies. Target hosts for employing systemic insecticides/drugs were animals (44.2\%, including rabbit, cattle, pig, and livestock) and humans (32.35\%).

Conclusions: Laboratory and field studies have highlighted the potential of endectocides in malaria control. Ivermectin and other endectocides could soon serve as novel malaria transmission control tools by reducing the longevity of Anopheles mosquitoes that feed on treated hosts, potentially decreasing Plasmodium parasite transmission when used as mass drug administration (MDA).
\end{abstract}

Keywords: Ivermectin, Endectocides, Systemic insecticides, Malaria elimination

\section{Background}

Malaria is a parasitic infectious disease of poverty and one of the major global public health problems [1]. Long-lasting insecticidal nets (LLINs), IRS, artemisinin combination therapy, transmission-blocking vaccines,

\footnotetext{
*Correspondence: saber@umsu.ac.ir; sabergholizadeh@yahoo.com 'Social Determinants of Health Research Center, Clinical Research Institute, Urmia University of Medical Sciences, Urmia, Iran

${ }^{2}$ Medical Entomology Department, School of Public Health, Urmia University of Medical Sciences, Urmia, Iran

Full list of author information is available at the end of the article
}

the deployment of single, low-dose primaquine, and antimalarial drugs are several WHO-recommended strategies in reducing the burden of malaria $[2,3]$. The widespread and sustained use of pesticides for malaria control has resulted in varied environmental and entomological issues mainly the selection of Anopheles mosquitoes for resistance to the primary vector control strategies $[4,5]$. Systemic insecticides are favorable solutions against insecticide-resistant and zoophilic/zoophagic mosquitoes [6].

C C The Author(s). 2021 Open Access This article is licensed under a Creative Commons Attribution 4.0 International License, which permits use, sharing, adaptation, distribution and reproduction in any medium or format, as long as you give appropriate credit to the original author(s) and the source, provide a link to the Creative Commons licence, and indicate if changes were made. The images or other third party material in this article are included in the article's Creative Commons licence, unless indicated otherwise in a credit line to the material. If material is not included in the article's Creative Commons licence and your intended use is not permitted by statutory regulation or exceeds the permitted use, you will need to obtain permission directly from the copyright holder. To view a copy of this licence, visit http://creativecommons.org/licenses/by/4.0/ The Creative Commons Public Domain Dedication waiver (http://creativecommons.org/publicdomain/zero/1.0/) applies to the data made available in this article, unless otherwise stated in a credit line to the data. 
Systemic insecticides are applied in veterinary, horticulture [7], and recent medical entomology [8]. Reports on the development of resistance to systemic insecticides in pests are scarce $[9,10]$. Among the 21 vector control tools evaluated in a review (shrinkingthemalariamap. org), less than 10 were supported by phase II or phase I evaluation of ivermectin, fipronil, and eprinomectin as endectocide administration in humans/animals, showing the rich pipeline of research into them at earlier stages of evaluation [11]. Endectocides are drugs applied directly to hosts to kill endoparasites and ectoparasites, mainly blood-feeding arthropods [12]. Although being used for the control of nematodes in humans and other vertebrates, endectocides can be toxic to Anopheles spp. when mosquitoes feed on a host recently received these drugs [13].

There are various advantages for systemic insecticides, including commercially available and easily accessible, relatively inexpensive, easy to administer in oral formulations, long-lasting, circulate uniformly in the blood for consistent vector uptake, have good safety, collateral benefits to treated animals [14]. However, the main concern in the wider scale application of them is related to the risk assessment of systemic insecticides in ecosystem functioning and services. There are several examples of the negative impact of these compounds on decomposition, nutrient cycling, soil respiration, and invertebrate population [15].

The role of livestock in malaria epidemiology is diverting malaria vectors to dead-end host and prevent parasite amplification by zooprophylaxis [16]. For this purpose, animals must be kept close to the man; therefore, it can increase malaria transmission by zoopotentiation, increasing the numbers of mosquitoes by keeping animals close to humans $[16,17]$ in areas where cattle production is semi-intensive or semi-extensive. However, social local factors in animal husbandry, scale of animal husbandry, and subsequent influence on the potential use of the endectocides need to be considered. The use of endectocides treated cattle as complementary intervention highly attractive in areas where humans and animals are close together, especially when the malaria mosquito is zoophagic such as An. arabiensis [18].

In the current review, published papers related to the application of systemic insecticides and endectocides for malaria vectors and parasites and their potential role as a new intervention for malaria elimination are discussed.

\section{Methods}

The protocol of the current study was conducted according to the checklist and guidelines of the Preferred Reporting Items for Systematic Reviews and MetaAnalyses (PRISMA) statement [19] (Supp. 1). Electronic databases, such as MEDLINE via PubMed, Web of
Science, and Scopus, were searched for relevant primary studies until 2019. English language publications were eligible and conference abstracts were not eligible for inclusion. The selection of studies based on their title and abstract was performed using Endnote X9 (Bld12062) and full-text publication was reviewed carefully. Eligibility assessment was performed independently in an unblinded standardized manner by two reviewers. We developed a data extraction sheet (Table 2), one review author (FG) extracted the following data from the included studies, and the second author (SG) checked the extracted data. Duplicate and ineligible studies were eliminated from further review. Disagreement on the eligibility of studies was resolved by discussion or consensus. A limited update literature search was performed on 17 November 2020. Although we had planned to assess reporting bias, there were too few included studies considering the same intervention to allow this to be done.

Information was extracted from each paper on (1) Anopheles species and the inclusion and exclusion criteria; (2) type of intervention including the type of systemic insecticides, dose, and host; and (3) type of outcome measure including survival rate, sporontocidal effect, reproduction rate, and malaria transmission.

The relative risk of mosquito mortality increasing, egg production reduction, and malaria transmission reduction was the primary measure of treatment effect. The nature of the included studies meant that much of the analysis was anticipated to be narrative. The data of studies were not combined and assume no serious inconsistency.

\section{Results}

The searches included 117 published papers on systemic insecticides and malaria control. Eight insecticides were applied mostly in different studies (Table 1). Doramectin, moxidectin, eprinomectin, and ivermectin (IVM) were used as primary endectocides in malaria control studies. IVM was also assessed as a systemic insecticide in $74 \%$ of the extracted papers on vector control.

During 1991-2019, there were 36 published papers regarding the application of systemic insecticides/endectocides for mosquito control in human and animal models (Fig. 1). In most studies (91.42\%), IVM was employed against Anopheles species. The Anopheles species names and their response to endectocides and promising results are presented in Table 2 in detail. Nearly half of the studies (56.75\%) were conducted on An. gambiae complex species. The standard dose for IVM MDA is $150 \mu \mathrm{g} / \mathrm{kg}$, but different doses (from $150 \mu \mathrm{g} / \mathrm{kg}$ to $400 \mu \mathrm{g} / \mathrm{kg}$ ) were assessed in several studies. Target hosts for employing systemic insecticides/drugs were animals (44.2\%, including rabbit, cattle, pig, and livestock) and humans (32.35\%); however, artificial membrane feeding, 
Table 1 Details of components used as systemic insecticides in this review

\begin{tabular}{|c|c|c|c|}
\hline Insecticides & Chemical class & Mode of action & Reference \\
\hline Afoxolaner & Isoxazolines & Antagonists of GABA- and glutamate-gated chloride channels. & [14] \\
\hline Fluralaner & & & [20] \\
\hline Sarolaner & & & {$[21,22]$} \\
\hline Diflubenzuron & IGR & Involves inhibiting the production of chitin & [12] \\
\hline Eprinomectin & $\begin{array}{l}\text { Macrocyclic lactones of microbial occurring } \\
\text { or avermectins }\end{array}$ & Chloride channel activators & [23] \\
\hline Spinosad & Macrocyclic lactones of microbial happening & Nicotinic acetylcholine receptor agonist & [20] \\
\hline Fipronil & Phenylpyrazole & The antagonist of GABA- and glutamate-gated chloride channels. & [24] \\
\hline Imidacloprid & Neonicotinoids & Nicotinic acetylcholine receptor agonist & [23] \\
\hline
\end{tabular}

IGR Insect growth regulator

toxic sugar bait, and bioassays against third instar mosquito larvae were utilized for the remaining $23.45 \%$ (Table 2).

\section{Anopheles gambiae complex species}

Application of a single oral dose of IVM $(200 \mathrm{mg} / \mathrm{kg})$ to An. gambiae fed on human volunteers displayed that IVM is a safe drug and can kill $89 \%$ of An. gambiae mosquitoes 4 days after the drug administration [25]. IVM
MDA on An. gambiae in Southeastern Senegal considerably diminished the survivorship of mosquitoes for 6 days past the date of the MDA [26]. Among eprinomectin, selamectin, moxidectin, N-tert-butyl nodulisporamide, and IVM, only eprinomectin killed An. gambiae mosquitoes at concentrations close to IVM [27]. Combining IVM with antimalarial drugs (artemether-lumefantrine $[\mathrm{AL}]$ ) in a double-blind, placebo-controlled trial lowered the likelihood of malaria transmission by An. gambiae after a single-

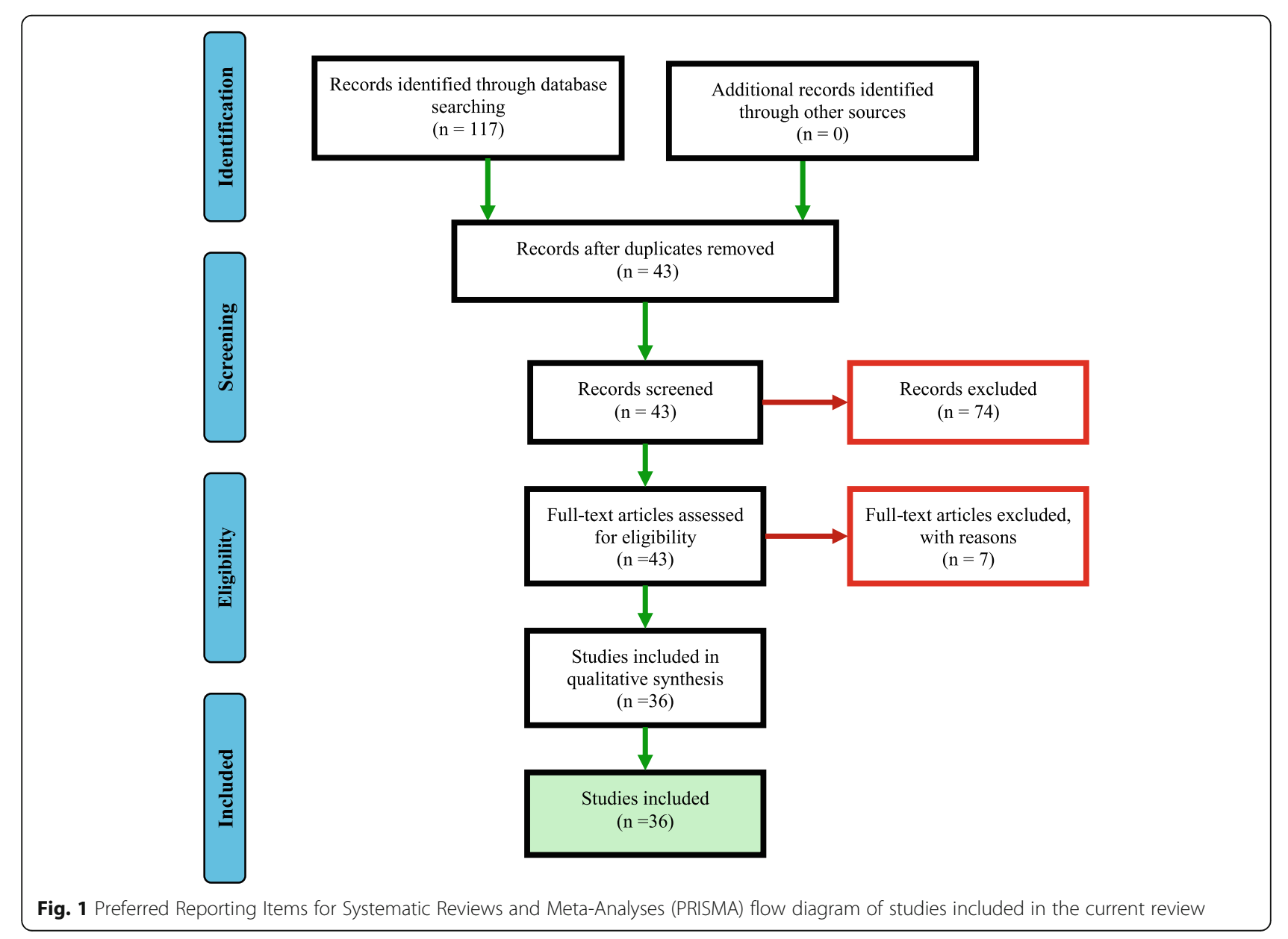




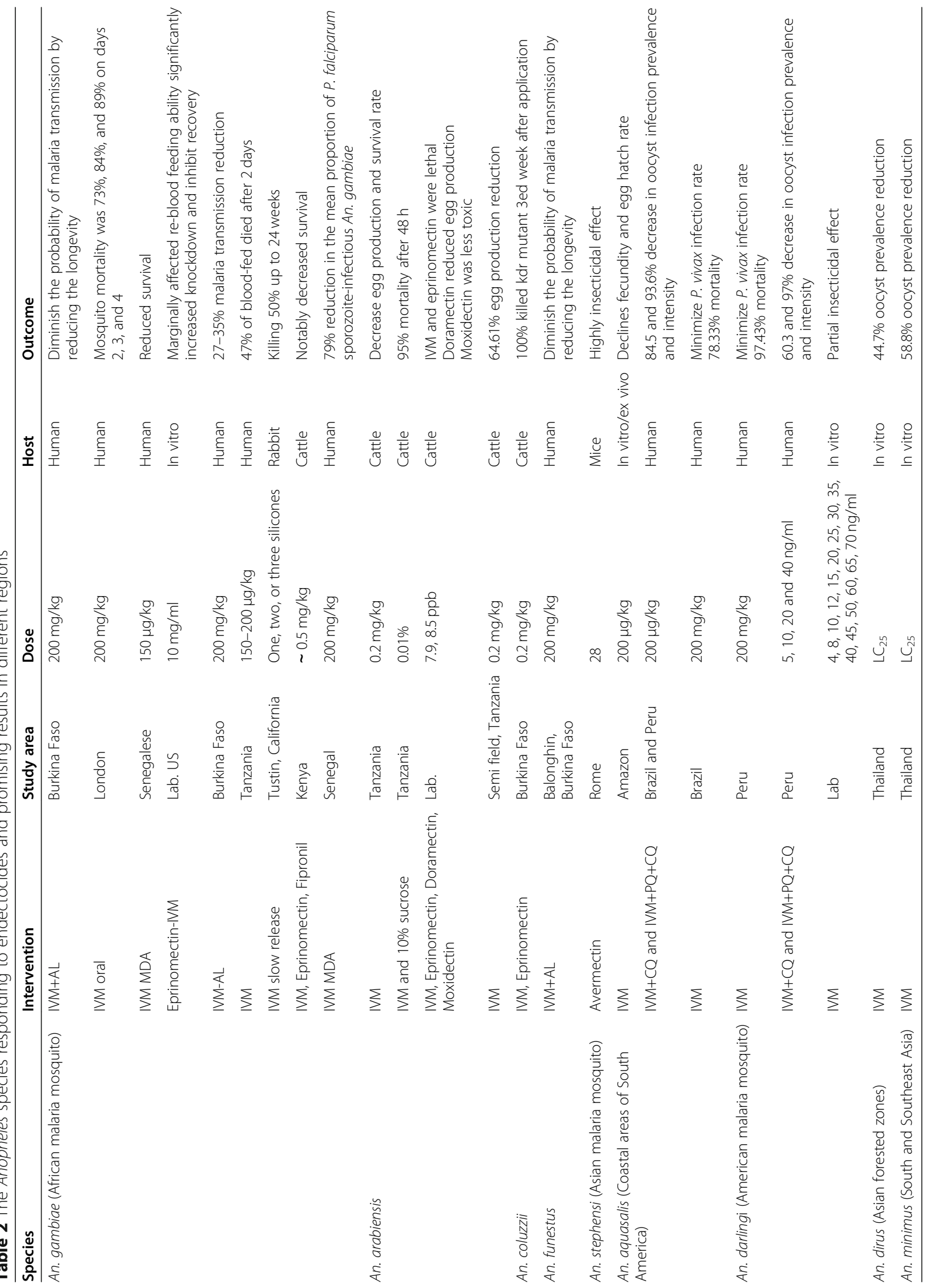


or repeated-dose $(200 \mathrm{mg} / \mathrm{kg})$ treatment of IVM to $27 \%$ and 35\% during the first week after treatment [28]. The effect of aging and prior blood feeding of An. gambiae on IVM susceptibility at 2,6 , and 14 days post-emergence (DPE) demonstrated increased susceptibility of An. gambiae mosquitoes (6 DPE) to IVM, particularly if they had previously been fed with blood [29]. Derua et al. (2015) assessed and compared the influence of human IVM treatment on blood-feeding An. gambiae. More than 47\% of the bloodfed An. gambiae in the IVM group died after 2 days of blood feeding compared to the placebo group (97.2\%).

The indirect impact of IVM MDA on malaria transmission by $A n$. gambiae was studied in five villages in the Sudano-Guinean phytogeographic zone of Senegal [30]. Comparison of the rate of sporozoite in An. gambiae species collected from treated and untreated villages indicated a 79\% reduction in the mean proportion of $P$. falciparum infection, while $P$. falciparum infection increased $246 \%$ in control villages [30]. Applying two IVM concentrations $\left(\mathrm{LC}_{25}\right.$ and $\left.\mathrm{LC}_{5}\right)$ along with cultured $P$. falciparum NF54 at 0, 3, 6, and 9 days post parasite injection signified that the IVM administration at sublethal dose inhibits the sporogony of $P$. falciparum in An. gambiae in laboratory conditions [30, 31].

Administration of AL plus placebo or AL plus $200 \mu \mathrm{g} /$ kg of IVM to asymptomatic P. falciparum carriers, An. gambiae and An. funestus, using the membrane feeding method demonstrated that IVM in combination with AL can diminish the probability of malaria transmission by reducing the longevity of blood-feeding mosquitoes in the first week after the initiation of treatment [28]. In a modeling study, the combination of IVM with AL resulted in the reduction and interruption of malaria transmission [12].

The concept of using slow-release IVM is relatively new and unique. Chaccour et al. (2015) designed and screened three different slow-release IVM formulations, including a silicone implant containing deoxycholate and sucrose. This formulation can release IVM for more than 12 weeks and is capable of killing 50\% of An. gambiae feeding on a treated rabbit for up to 24 weeks. These observations denote that silicone-based subcutaneous formulation of IVM can safely be sustained in rabbits for up to 6 months [32]. Subcutaneous administration of slow-release IVM implant formulation in pig and cattle enhanced the level of insecticide in the host's blood and sustained it stable for 6 months, thereby killing An. gambiae and An. arabiensis mosquitoes [33, 34].

In vitro feeding of laboratory-reared An. arabiensis with cattle parasiticides viz. IVM, eprinomectin, doramectin, and moxidectin revealed that IVM $\left(\mathrm{LC}_{50}\right.$ of $\left.7.9 \mathrm{ppb}\right)$ and eprinomectin ( $\mathrm{LC}_{50}$ of $8.5 \mathrm{ppb}$ ) were lethal to An. arabiensis. Doramectin markedly reduced egg development in this species. Moxidectin, however, was more than 100-fold weaker than other abovementioned insecticides, to reduce survivorship and egg production in An. arabiensis. Moxidectin had also a less toxic effect on $A n$. arabiensis relative to the other three chemicals [35]. In Western Kenya, determination of IVM, eprinomectin, and fipronil on the survival of An. arabiensis disclosed that all the three compounds notably decreased the An. arabiensis survival [36, 37]. The effects of IVM-treated cattle on An. arabiensis population under the semi-field conditions in Southeastern Tanzania displayed a significant diminution in blood meal digestion, egg production (up to 15 days), and survival time (1-3 days) and also a fivefold increase in mortality in the first week [38]. Alternatively, the application of a $10 \%$ sucrose solution containing $0.01 \%$ IVM against An. arabiensis killed approximately $95 \%$ of mosquitoes 48 h post sugar feeding [39]. Endectocidal treatments of animals and/or humans could be a favorable new strategy for control of residual, outdoor malaria transmission. The impact of An. arabiensis feeding on rabbits treated with different doses of IVM on mosquito mortality exhibited that the recommended dose $(1 \mathrm{ml} / 50 \mathrm{k})$ was more effective than $25 \%$ higher and $25 \%$ lower of the recommended dose in mosquito-killing mosquitos [40]. IVM-treated cattle significantly reduced egg production $(64.61 \%)$ of a freeliving population of An. arabiensis under semi-field conditions with various feeding times. The egg production rates were $54.64 \%, 74.14 \%, 76.87 \%$, and $81.62 \%$ at days $3,6,9$, and 12 , respectively, and then it decreased gradually until 15 days post-treatment [38].

Administration of IVM to cattle with an injectable therapeutic dose $(0.2 \mathrm{mg} / \mathrm{kg})$ increased the mortality of $A n$. coluzzii carrying the $k d r$ mutation up to $100 \%$ in the third week after the initial injection with a second blood meal of IVM [41]. Sub-lethal concentrations of IVM decreased by $33 \%$ and $36 \%$ of egg production between days 21 and 28 after injection into An. coluzzii fed on cattle treated with $0.2 \mathrm{mg} / \mathrm{kg}$ of IVM [41].

These results suggest that IVM and eprinomectin could be used to control zoophilic malaria vectors and reduce their population size.

\section{Anopheles stephensi}

For the first time in 1985, two avermectin compounds, MK-933 and MK-936, were used for mosquito control [42]. To this end, $2.8 \mathrm{mg} / \mathrm{l}$ of avermectin was applied against the larvae of An. stephensi. When An. stephensi mosquitoes were fed on MK-933-treated mice and 5\% sucrose solution in $0.14,0.28,2.8$, and $28 \mathrm{mg} / \mathrm{kg}$ dosages, high insecticidal activity occurred in sucrose solution $(28 \mathrm{mg} / \mathrm{kg})$ [42].

\section{An. aquasalis and An. darlingi}

Ex vivo evaluation of the IVM effect on An. aquasalis and An. darlingi minimized the infection rate of $P$. vivax 
in both species and maximized the mortality of mosquitoes $(78.33 \%$ and $97.43 \%$, respectively) $4 \mathrm{~h}$ post blood meal ingestion [43]. In vivo assessment of An. aquasalis susceptibility to IVM on three male and three female volunteers revealed that this drug could raise the mosquito mortality when blood feeding on a human host from $4 \mathrm{~h}$ to 14 days post-ingestion. IVM at mosquito sub-lethal concentrations $\left(\mathrm{LC}_{5}\right)$ reduced fecundity and egg hatch rate, but not the number of pupae developed from larvae [44]. Based on a report in 2018, the oocyst infection prevalence and intensity were decreased by $60.3 \%$ and $97 \%$ in An. darlingi and $84.5 \%$ and $93.6 \%$ in An. aquasalis, respectively, when mosquitoes ingested blood from $P$. vivax patients that ingested IVM + CQ (chloroquine), $\mathrm{PQ}$ (primaquine) $+\mathrm{CQ}$, and $\mathrm{IVM}+\mathrm{PQ}+$ CQ [43].

\section{An. dirus and An. minimus}

When IVM offered to An. dirus and An. minimus along with human $P$. vivax-infected blood, oocyst prevalence reduced by $44.7 \%$ and $58.8 \%$ in $\mathrm{LC}_{25}$ and $33.6 \%$ and $31.3 \%$ in $\mathrm{LC}_{5}$, respectively. IVM hinders the $P$. vivax sporogony development in An. dirus and An. minimus in the $\mathrm{LC}_{25}$ and $\mathrm{LC}_{5}$ concentrations [31]. Effect of IVM on $P$. vivax oocyst infection in An. darling in the laboratory was attributed at least partly to the insecticidal effect, as shown by the age shift in the mosquito population [31].

\section{Discussions}

The present review has focused on the recent applications of systemic insecticides and drugs for malaria control; however, most of them were related to IVM. It could be postulated that the main goal of these studies, directly and indirectly, was focused on nine Anopheles malaria vectors in different zoogeographical regions including An. gambiae, An. arabiensis, An. coluzzii, An. stephensi, An. aquasalis, An. dirus, An. darlingi, An. funestus, and An. minimus. They have evaluated the efficiency of endectocides on the Anopheles survival rate, sporontocidal effect, reproduction rate, and malaria transmission.

IVM has been applied in different formulations and combinations such as singly, in combination with other endectocides, antimalarial drugs, sucrose, and MDA. However, their results were satisfactory and acceptable, and none of them showed 100\% efficacy against different malaria vectors (Table 2). Vector control methods target the single chain of malaria transmission cycle, and candidate vaccines are still unavailable. However, for successful control goals of malaria 2016-2030, novel methods are highly needed to target the malaria transmission cycle and break its chain. In view of the fact that the current methods are inadequate for reaching the
WHO Global Technical Strategy for Malaria 2016-2030, goals aim at reducing malaria mortality rates by at least $90 \%$, controlling and eliminating malaria in at least 35 countries, and preventing the resurgence of the disease in malaria-free countries.

Taken together, candidate components of a secondgeneration malaria vaccine are emerging, and efforts are underway to develop a regional malaria vaccine. Moreover, simultaneously with the development of molecular markers in Anopheles species detection and introducing new species complexes such as An. stephensi [45-47], assessment of these components is crucial.

\section{Conclusion}

It was suggested that following the WHO reports on the endectocides as vector control tools [1], a roadmap provided that ivermectin will be available as a vector control tool by 2024 [48]. Therefore, due to considerable advantages such as low price, killing the mosquito by blood feeding from the host, reduction in the sporozoite rate, endectocides, and systemic drugs could be suggested to achieve this goal. Endectocide could be suggested as a complementary intervention in malaria control and elimination programs.

Different systematic reviews of the effect of systemic insecticides on malaria disease were published. All confirmed a significant reduction in infections, though effects on the Anopheles survival rate, sporontocidal effect, reproduction rate, and malaria transmission, separately. The results were varied from one review to another. Near to all of the studies have been done in lab or semifield conditions. The estimated impact on overall infection reduction was obtained after doing experiments in field conditions, a logical next step for future trials.

\section{Limitations}

The systematic review reported here combines data across studies to estimate the effects of systemic insecticides on different malaria vectors in different zoogeographical regions. The main limitation of this systematic review, as with any overview, is that the Anopheles populations, the systemic insecticide application method, and regimen are not the same across studies.

\section{Supplementary Information}

The online version contains supplementary material available at https://doi. org/10.1186/s13643-021-01578-9.

Additional file 1:. PRISMA 2019 checklist

Additional file 2: Table S1. Keywords used in the database search

Additional file 3: Table S2. Exclusion and inclusion criteria

\section{Abbreviations}

VBD: Vector-borne diseases; IVM: Ivermectin; IRs: Indoor residual spraying;

ITNs: Insecticide-treated nets; MDA: Mass drug administration; MeSH: Medical 
subject heading; DPE: Days post-emergence; LC: Lethal concentrations; SIT: Sterile insect techniques; MFA: Membrane feeding assay; DFA: Direct feeding assay; AL: Artemether-lumefantrine; MEDLINE: Medical literature analysis and retrieval system online; PRISMA: Preferred reporting items for systematic review and meta-analysis

\section{Acknowledgements}

The authors express their gratitude to the Cellular and Molecular Research Center, Urmia University of Medical Sciences in Iran, and All-Russian Scientific Research Institute of Veterinary Entomology and Arachnology - Branch of Federal State Institution Federal Research Centre Tyumen Scientific Centre of Siberian Branch of the Russian Academy of Sciences (ASRIVEA - Branch of Tyumen Scientific Centre SB RAS) in Russia.

\section{Authors' contributions}

Conceived and designed the study: SG and FG. Search and data selection: FG and SG. analyzed the data: SG, FG, BR, AJ, ES, and ML. Wrote the paper: $\mathrm{SG}, \mathrm{FG}, \mathrm{BR}, \mathrm{AJ}, \mathrm{ES}$, and $\mathrm{ML}$. All authors read and approved the final manuscript.

\section{Funding}

This review did not need a financial source.

\section{Availability of data and materials}

Data supporting this article are included within the article and supplementary file.

\section{Ethics approval and consent to participate}

Not applicable

\section{Consent for publication}

Not applicable

\section{Competing interests}

The authors declare that they have no competing interests.

\section{Author details}

${ }^{1}$ Social Determinants of Health Research Center, Clinical Research Institute, Urmia University of Medical Sciences, Urmia, Iran. ${ }^{2}$ Medical Entomology Department, School of Public Health, Urmia University of Medical Sciences, Urmia, Iran. ${ }^{3}$ Department of Clinical Toxicology, School of Medicine, Urmia University of Medical Sciences, Urmia, Iran. ${ }^{4}$ Cellular and Molecular Research Center, Research Institute on Cellular and Molecular Medicine, Urmia University of Medical Sciences, Urmia, Iran. ${ }^{5}$ All-Russian Scientific Research Institute of Veterinary Entomology and Arachnology, Branch of Federal State Institution Federal Research Centre Tyumen Scientific Centre, Siberian Branch of the Russian Academy of Sciences (ASRIVEA - Branch of Tyumen Scientific Centre SB RAS), Institutskaya st. 2, Tyumen, Russian Federation 625041. ${ }^{6}$ Department of Health Information Technology, School of Applied Medical Sciences, Urmia University of Medical Sciences, Urmia, Iran.

Received: 7 September 2020 Accepted: 2 January 2021 Published online: 18 January 2021

\section{References}

1. WHO. World malaria report 2018. Geneva: World Health Organization; 2018.

2. Barber BE, Rajahram GS, Grigg MJ, William T, Anstey NM. World Malaria Report: time to acknowledge Plasmodium knowlesi malaria. Malar J. 2017; 16(1):1-3.

3. Bhatt S, Weiss DJ, Cameron E, Bisanzio D, Mappin B, Dalrymple U, Battle KE, Moyes CL, Henry A, Eckhoff PA, Wenger EA. The effect of malaria control on Plasmodium falciparum in Africa between 2000 and 2015. Nature. 2015; 526(7572):207-11.

4. Teng WC, Kiat HH, Suwanarusk R, Koh HL. Medicinal plants and malaria: applications, trends, and prospects. Florida: CRC Press; 2016.

5. Moorthy VS, Hutubessy R, Newman RD, Hombach J. Decision-making on malaria vaccine introduction: the role of cost-effectiveness analyses. Bull World Health Organ. 2012;90:864-6.

6. Chaccour $\mathrm{Cl}$, Rabinovich NR Oral, slow-release ivermectin: biting back at malaria vectors. Trends Parasitol. 2017;1(33):156-8.
7. Simon JY. The toxicology and biochemistry of insecticides: 2nd edition. Poca Raton: CRC press; 2011.

8. Yadav I, Devi NL. Pesticides classification and its impact on human and environment. Environ Sci Eng. 2017:6:140-158

9. Abbas N, Shad SA, Shah RM. Resistance status of Musca domestica L. populations to neonicotinoids and insect growth regulators in Pakistan poultry facilities. Pak J Zool. 2015;47(6):1663-71.

10. Bass C, Denholm I, Williamson MS, Nauen R. The global status of insect resistance to neonicotinoid insecticides. J Pestic Biochem Physiol. 2015;121: 78-87.

11. Meredith HR, Furuya-Kanamori L, Yakob L. Optimising systemic insecticide use to improve malaria control. BMJ Glob Health. 2019;4(6):e001776.

12. Yakob L. Endectocide-treated cattle for malaria control: a coupled entomologicalepidemiological model. Parasite Epidemiol Control. 2016;1(1):2-9.

13. Foy BD, Kobylinski KC, da Silva IM, Rasgon JL, Sylla M. Endectocides for malaria control. Trends Parasitol. 2011;27(10):423-8.

14. Loza A, Talaga A, Herbas G, Canaviri RJ, Cahuasiri T, Luck L, Guibarra A, Goncalves R, Pereira JA, Gomez SA. Systemic insecticide treatment of the canine reservoir of Trypanosoma cruzi induces high levels of lethality in Triatoma infestans, a principal vector of Chagas disease. Parasites Vectors. 2017;10(1):344.

15. Chagnon M, Kreutzweiser D, Mitchell EA, Morrissey CA, Noome DA, Van der Sluijs JP. Risks of large-scale use of systemic insecticides to ecosystem functioning and services. Environ Sci Pollut Res. 2015;22(1):119-34.

16. Donnelly B, Berrang-Ford L, Ross NA, Michel P. A systematic, realist review of zooprophylaxis for malaria control. Malar J. 2015;14:313.

17. Saul A. Zooprophylaxis or zoopotentiation: the outcome of introducing animals on vector transmission is highly dependent on the mosquito mortality while searching. Malar J. 2003:2:32

18. Imbahale SS, Montana Lopez J, Brew J, Paaijmans K, Rist C, Chaccour C. Mapping the potential use of endectocide-treated cattle to reduce malaria transmission. Sci Rep. 2019:9(1):5826.

19. Hutton B, Salanti G, Caldwell DM, Chaimani A, Schmid CH, Cameron C, loannidis JP, Straus S, Thorlund K, Jansen JP. The PRISMA extension statement for reporting of systematic reviews incorporating network metaanalyses of health care interventions: checklist and explanations. Ann Intern Med. 2015;162(11):777-84.

20. Gomez SA, Picado A. Systemic insecticides used in dogs: potential candidates for phlebotomine vector control? Trop Med Int Health. 2017; 22(6):755-64.

21. McTier TL, Chubb N, Curtis MP, Hedges L, Inskeep GA, Knauer CS, Menon S, Mills B, Pullins A, Zinser EJ. Discovery of sarolaner: a novel, orally administered, broad-spectrum, isoxazoline ectoparasiticide for dogs. Vet Parasitol. 2016;222:3-11.

22. Weber T, Selzer PM. Isoxazolines: a novel chemotype highly effective on ectoparasites. ChemMedChem. 2016;11(3):270-6.

23. Simon JY. The toxicology and biochemistry of insecticides: 2 nd edition. Poca Raton: CRC Press; 2014.

24. Leirs H, Larsen K, Lodal J. Palatability and toxicity of fipronil as a systemic insecticide in a bromadiolone rodenticide bait for rat and flea control. Med Vet Entomol. 2001;15(3):299-303.

25. Chaccour C, Lines J, Whitty CJ. Effect of ivermectin on Anopheles gambiae mosquitoes fed on humans: the potential of oral insecticides in malaria control. J Infect Dis. 2010;202(1):113-6.

26. Sylla M, Kobylinski KC, Gray M, Chapman PL, Sarr MD, Rasgon JL, Foy BD. Mass drug administration of ivermectin in south-eastern Senegal reduces the survivorship of wild-caught, blood fed malaria vectors. Malari J. 2010; $9(1): 365$.

27. Butters MP, Kobylinski KC, Deus KM, Da Silva IM, Gray M, Sylla M, Foy BD. Comparative evaluation of systemic drugs for their effects against Anopheles gambiae. Acta Trop. 2012;121(1):34-43.

28. Ouédraogo AL, Bastiaens GJ, Tiono AB, Guelbéogo WM, Kobylinski KC, Ouédraogo A, Barry A, Bougouma EC, Nebie I, Ouattara MS. Efficacy and safety of the mosquitocidal drug ivermectin to prevent malaria transmission after treatment: a double-blind, randomized, clinical trial. Clin Infect Dis. 2015:60(3):357-65.

29. Seaman JA, Alout H, Meyers Jl, Stenglein MD, Dabiré RK, LozanoFuentes S, Burton TA, Kuklinski WS, Black WC, Foy BD. Age and prior blood feeding of Anopheles gambiae influences their susceptibility and gene expression patterns to ivermectin-containing blood meals. BMC Genomics. 2015;16(1):797. 
30. Kobylinski KC, Sylla M, Chapman PL, Sarr MD, Foy BD. Hygiene: Ivermectin mass drug administration to humans disrupts malaria parasite transmission in Senegalese villages. Am J Trop Med Hyg. 2011;85(1):3-5.

31. Kobylinski KC, Escobedo-Vargas KS, Lopez-Sifuentes VM, Durand S, Smith ES, Baldeviano GC, Gerbasi RV, Ballard S-B, Stoops CA, Vásquez GM. Ivermectin susceptibility, sporontocidal effect, and inhibition of time to re-feed in the Amazonian malaria vector Anopheles darlingi. Malar J. 2017;16(1):474.

32. Chaccour C, Barrio Ál, Royo AGG, Urbistondo DM, Slater H, Hammann F, Del Pozo JL. Screening for an ivermectin slow-release formulation suitable for malaria vector control. Malar J. 2015;14(1):102.

33. Chaccour C, Abizanda G, Irigoyen A, Del Pozo JL. Pilot study of a slowrelease ivermectin formulation for malaria control in a pig model. Antimicrobial Agents Chemother. 2017;61(3):e02104-16.

34. Chaccour CJ, Ngha'bi K, Abizanda G, Barrio Al, Aldaz A, Okumu F, Slater H, Del Pozo JL, Killeen G. Targeting cattle for malaria elimination: marked reduction of Anopheles arabiensis survival for over six months using a slowrelease ivermectin implant formulation. Parasit Vectors. 2018;11(1):287.

35. Fritz ML, Walker ED. Miller JR. Lethal and sublethal effects of avermectin/ milbemycin parasiticides on the African malaria vector, Anopheles Arabiensis. J Med Entomol. 2012:49(2):326-31.

36. Poché RM, Burruss D, Polyakova L, Poché DM, Garlapati RB. Treatment of livestock with systemic insecticides for control of Anopheles arabiensis in western Kenya. Malar J. 2015;14(1):351.

37. Lozano-Fuentes S, Kading RC, Hartman DA, Okoth E, Githaka N, Nene V, Poché RM. Evaluation of a topical formulation of eprinomectin against Anopheles arabiensis when administered to Zebu cattle (Bos indicus) under field conditions. Malar J. 2016;15(1):324.

38. Lyimo IN, Kessy ST, Mbina KF, Daraja AA, Mnyone LL. Ivermectin-treated cattle reduces blood digestion, egg production and survival of a free-living population of Anopheles arabiensis under semi-field condition in southeastern Tanzania. Malar J. 2017;16(1):239.

39. Tenywa FC, Kambagha A, Saddler A, Maia MF. The development of an ivermectin-based attractive toxic sugar bait (ATSB) to target Anopheles arabiensis. Malar J. 2017;16(1):338.

40. Ramadan NM. Effect of feeding on blood of rabbits treated with ivermectin on female Adults of Anopheles arabiensis Patton (Diptera: Culicidae), 2018 (Doctoral dissertation, University of Gezira).

41. Pooda HS, Rayaisse J-B, de Sale Hien DF, Lefèvre T, Yerbanga SR, Bengaly Z, Dabiré RK, Belem AM, Sidibé I, Solano P. Administration of ivermectin to peridomestic cattle: a promising approach to target the residual transmission of human malaria. Malar J. 2015;14(1):496.

42. Pampiglione S, Majori G, Petrangeli G, Romi R. Hygiene: Avermectins, MK-933 and MK-936, for mosquito control. Trans R Soc Trop Med. 1985;79(6):797-9.

43. Pinilla YT, Lopes SC, Sampaio VS, Andrade FS, Melo GC, Orfanó AS, Secundino NF, Guerra MG, Lacerda MV, Kobylinski KC. Promising approach to reducing Malaria transmission by ivermectin: sporontocidal effect against Plasmodium vivax in the South American vectors Anopheles aquasalis and Anopheles darlingi. PLoS Negl Trop Dis. 2018;12(2):e0006221.

44. Sampaio VS, Beltrán TP, Kobylinski KC, Melo GC, Lima JB, Silva SG, Rodriguez IC, Silveira H, Guerra MG, Bassat Q. Filling gaps on ivermectin knowledge: effects on the survival and reproduction of Anopheles aquasalis, a Latin American malaria vector. Malar J. 2016;15(1):491.

45. Firooziyan S, Djadid ND, Gholizadeh S. Speculation on the possibility for introducing Anopheles stephensi as a species complex: preliminary evidence based on odorant binding protein 1 intron I sequence. Malar J. 2018;17(1):366.

46. Gholizadeh S, Djadid ND, Nouroozi B, Bekmohammadi. Molecular phylogenetic analysis of Anopheles and Cellia subgenus anophelines (Diptera: Culicidae) in temperate and tropical regions of Iran. Acta Trop. 2013:126(1):63-74

47. Gholizadeh S, Firooziyan S, Ladonni H, Hajipirloo HM, Djadid ND, Hosseini A, Raz A. The Anopheles stephensi odorant binding protein 1 (AsteObp1) gene: a new molecular marker for biological forms diagnosis. Acta Trop. 2015;146:101-13.

48. Roadmappers I. A roadmap for the development of ivermectin as a complementary malaria vector control tool. Am J Trop Med Hyg. 2020; 102(2s):3-24.

\section{Publisher's Note}

Springer Nature remains neutral with regard to jurisdictional claims in published maps and institutional affiliations.

\section{Ready to submit your research? Choose BMC and benefit from:}

- fast, convenient online submission

- thorough peer review by experienced researchers in your field

- rapid publication on acceptance

- support for research data, including large and complex data types

- gold Open Access which fosters wider collaboration and increased citations

- maximum visibility for your research: over $100 \mathrm{M}$ website views per year

At BMC, research is always in progress.

Learn more biomedcentral.com/submissions 